University of Windsor

Scholarship at UWindsor

2016

\title{
A Classification System for Argumentation Schemes
}

Douglas Walton

University of Windsor, Centre for Research in Reasoning, Argumentation and Rhetoric

Fabrizio Macagno

Universidade Nova de Lisboa, ArgLab, Institute of Philosophy of Language (IFL)

Follow this and additional works at: https://scholar.uwindsor.ca/crrarpub

Part of the Arts and Humanities Commons

\section{Recommended Citation}

Walton, Douglas and Macagno, Fabrizio. (2016). A Classification System for Argumentation Schemes. Argument \& Computation, 1-29.

https://scholar.uwindsor.ca/crrarpub/38

This Article is brought to you for free and open access by the Centre for Research in Reasoning, Argumentation and Rhetoric (CRRAR) at Scholarship at UWindsor. It has been accepted for inclusion in CRRAR Publications by an authorized administrator of Scholarship at UWindsor. For more information, please contact scholarship@uwindsor.ca. 


\section{A classification system for argumentation schemes}

Article in Argument and Computation · April 2016

DOI: $10.1080 / 19462166.2015 .1123772$

READS

23

2 authors, including:

Fabrizio Macagno

New University of Lisbon

65 PUBLICATIONS 581 CITATIONS

SEE PROFILE 


\section{Argument \& Computation}

\section{A classification system for argumentation schemes}

\section{Douglas Walton \& Fabrizio Macagno}

To cite this article: Douglas Walton \& Fabrizio Macagno (2016): A classification system for argumentation schemes, Argument \& Computation, DOI: 10.1080/19462166.2015.1123772

To link to this article: http://dx.doi.org/10.1080/19462166.2015.1123772

曲 Published online: 19 Apr 2016.

Submit your article to this journal 저

Q View related articles $₫$

View Crossmark data $\nearrow$ 


\title{
A classification system for argumentation schemes
}

\author{
Douglas Walton $^{\mathrm{a} *}$ and Fabrizio Macagno ${ }^{\mathrm{b}}$ \\ ${ }^{a}$ Philosophy Department, CRRAR, University of Windsor, 401 Sunset Ave., Windsor, ON, Canada N9B \\ 3P4; ${ }^{b}$ Universidade Nova de Lisboa, Institute of Philosophy of Language, Avenida de Berna 26, \\ Lisbon, Portugal
}

(Received 2 December 2013; accepted 6 November 2015)

\begin{abstract}
This paper explains the importance of classifying argumentation schemes, and outlines how schemes are being used in current research in artificial intelligence and computational linguistics on argument mining. It provides a survey of the literature on scheme classification. What are so far generally taken to represent a set of the most widely useful defeasible argumentation schemes are surveyed and explained systematically, including some that are difficult to classify. A new classification system covering these centrally important schemes is built.
\end{abstract}

Keywords: argument representation; argument interpretation; computational models of natural language argument

Argumentation schemes are stereotypical patterns of reasoning (Walton, 1990) with a corresponding set of critical questions, namely defeasibility conditions. They represent patterns used in everyday conversational argumentation, and in other contexts such as legal and scientific argumentation. Among the schemes listed in the compendium of schemes in Chapter 9 of Walton, Reed, and Macagno (2008) are argument from expert opinion, argument from sign, argument from example, argument from commitment, argument from position to know, argument from lack of knowledge, practical reasoning (argument from goal to action), argument from cause to effect, the sunk costs (SC) argument, argument from analogy, ad hominem argument, and the slippery slope argument. Historically, schemes are the descendants of the topics of Aristotle. Many of them were identified by Hastings (1963), Perelman and Olbrechts-Tyteca (1969), Kienpointner (1992), Walton (1996), Grennan (1997), and Walton et al. (2008). The purpose of this paper is to contribute to the building of a method for classifying schemes (Macagno \& Walton, 2015).

It is shown that classifying schemes starts by studying relationships between groups of clusters of schemes. A cluster is a set of schemes shown to be closely related to each other, such as an instance where one scheme can be shown to be a subspecies of another. Relationships within such groups of schemes are studied, and then how one group fits with another can be studied. Approaching classification of schemes is also moved forward by formulating generalisations as hypotheses about categories that schemes fall into, and then modifying them in light of problematic cases that are hard to classify. Walton (2012) took a bottom-up approach that began with some examples at the ground level of cases where two schemes seem to apply to the same real example of an argument found in a text, leading to a difficulty of determining which scheme fits the argument. Once clusters of schemes are fitted together into larger groups, it can be seen how they fit into an overarching system. The new system is a refinement of the classification proposed in Walton et al. (2008, Chap. 10).

*Corresponding author. Email: dwalton@ uwindsor.ca 
The first two sections explain the importance of classifying schemes, and survey the uses of schemes in argument mining. Section 3 provides a survey of the literature on scheme classification. Section 4 discusses five ways of classifying schemes, and lists six desiderata for a classification system. Sections 5-8 analyse what are so far generally taken to be the widely useful schemes, showing how they are related to each other. Section 9 summarises the classification of Walton et al. (2008), and presents a refined and extended version of it as a graph structure. Section 10 provides some conclusions.

\section{Why argumentation schemes are important}

In any classification system, entities can be classified in many different ways, depending on the purpose of the classification (Macagno \& Walton, 2014a, Chap. 3). The purpose of the classification system will determine the criteria for classification that are adopted in that system. For example, a much more detailed classification of animals may be useful in biology than the kind of classification that might be useful for law, or for classifying animals as they are spoken and written about in everyday conversational English. Criteria that are useful for classifying animals in biology might be expected to be quite different from the kind of criteria needed to classify animals in law, or in everyday conversational speech. In addressing any proposal to classify argumentation schemes, we need to begin by specifying the purpose of the classification, so that some guidance can be given on how to identify the criteria used in the classification system (Macagno $\&$ Walton, 2015). From this perspective, it is useful to examine how the study of argumentation schemes evolved.

Work in the second half of the twentieth century on argumentation schemes began in the field of argumentation studies as an attempt to identify the kinds of arguments commonly used in everyday conversational examples of argumentation of the kind found for example in newspaper or magazine articles about politics, or indeed about any subjects of the kind we commonly argue about in daily life. The work that began to identify the schemes in a systematic way used everyday examples of argumentation. Many of the examples came from the newly emerging textbooks on informal logic that had the aim of teaching students how to identify, analyse, and evaluate arguments of the kind they would commonly be required to deal with in everyday life, personal deliberations, business transactions, and so forth (Grennan, 1997; Kienpointner, 1992; Walton, 1996). The purpose of using schemes was to help students identify the structure of commonly used arguments, so that they could specify the premises and conclusions of the argument in a systematic way, identify each specific type of argument as requiring a different kind of treatment, and critically question each type of argument in a distinctive way by asking standard critical questions appropriate for each scheme that probe into the weak points in that particular type of argument (Walton, 2011). The purpose of using schemes for this purpose was meant to be practical, and it was meant to be directed to helping students improve their skills in dealing with everyday conversational arguments.

There was already a corpus of such examples being built up in the logic textbooks that had sections on identifying, analysing, and evaluating arguments in everyday conversational discourse, and in special contexts of use like that of law and science. Many of these common arguments, like argument from analogy and argument from expert opinion, were associated with significant errors and misuses of the kind identified with informal fallacies. Already in these textbooks, there was a growing corpus of interesting examples. Also, as it was found through the experience of teaching logic, and writing textbooks that schemes could be practically useful in helping students to improve their argumentation skills (Duschl, 2008; Kim, Anthony, \& Blades, 2012; Nussbaum, 2011; Rapanta, Garcia-Mila, \& Gilabert, 2013), it was also found there were certain sorts of errors 
that students typically made (Rowe, Macagno, Reed, \& Walton, 2006). For example, they would mix up certain types of arguments. They might mix up different types of appeals to authority, confusing arguments from expert opinion with other types of appeals to authority not based on presumptions about expert knowledge. Or they might misidentify slippery slope arguments by seeing them as simply being arguments from negative consequences without realising that the slippery slope argument is much more complex, and requires a recursive premise to the effect that the process, once started, will repeat itself, leading to loss of control.

\section{Argument mining}

As it became known that argumentation schemes with sets of matching critical questions are proving to be useful for this purpose, other fields began to take an interest in them as well. Artificial intelligence began to see argumentation generally, and argumentation schemes in particular, as useful for building models of defeasible reasoning (Reed \& Walton, 2003). It became evident that argumentation tools, and once again particularly schemes, could be especially applicable to model legal argumentation, particularly in areas like evidential reasoning (Walton, 2002) or statutory interpretation (Sartor, Walton, Macagno, \& Rotolo, 2014).

Through these developments, some work was done on argument mining of legal databases to experimentally see if schemes could be used to identify and collect instances of a certain type of argument, like argument from expert opinion, or argument from precedent (Mochales \& Moens, 2011). Argument extraction, a procedure that can scan over a text and pick out arguments of certain types, such as those represented by argumentation schemes, would be an extremely useful tool for argumentation research. A technology for argument mining of legal texts (Mochales Palau \& Moens, 2009; Mochales \& Moens, 2011), using a corpus of legal arguments from texts of the European Court of Human Rights, has opened opportunities for applying schemes to text mining in a way that could be used to identify and collect arguments of known types. The practical usefulness of an automated tool that could search through databases and pick out all the arguments of a certain type is not hard to imagine. Its usefulness is enhanced by the existence of argument visualisation tools (Reed, Walton, \& Macagno, 2007) that can be applied to argumentative texts of discourse, yielding analyses of arguments that display schemes in the structure. Argument extraction is closely related to the project of argument scheme classification. It would be very useful for setting up projects of argument mining to have a classification system showing how one scheme can precisely be classified as a subspecies of another scheme that it is closely related to. Classification is useful for argument mining because of the borderline cases, as will be illustrated in this paper.

This work, in turn, suggested the possibility that schemes could also be used to search through databases containing everyday conversational argumentation of the kind found on the Internet, for example (Walton, 2011). Hansen and Walton (2013) took first steps to use schemes to identify types of arguments used in an election campaign. The possibility of developing computational tools that could be used for this purpose was very exciting for argumentation theory itself, as an interdisciplinary subject, because it suggested that, instead of having to identify these arguments in a corpus by using coders that need to have three or four years of training in argumentation before they are skilled enough to be able to pick out examples of each type of argument, we could carry out this kind of data collection as an automated procedure. At least the procedure could be considerably expedited even if it was only semi-automated. Even if the machine collected a lot of false positives, the coders could still much more quickly collect examples of specified types of arguments by sorting through the findings to pick out the interesting examples.

So far the most attention to the use of argumentation schemes has been paid in legal argumentation, but recently there has been some work done on schemes used in everyday conversational 
argumentation, specifically, political argumentation in election campaigns. Many of the arguments used in law, for example, arguments used by both sides in a common-law trial, are very closely related to comparable arguments used in everyday conversational argumentation. Legal reasoning typically requires a variety of argumentation schemes to be used together. Gordon and Walton (2009a) showed how instances of arguments used in legal cases of kinds like argument from precedent cases, rules, policy goals, moral principles, social values, and evidence can be modelled using argumentation schemes. Prakken (2010) studied the use of hypothetical and value-based reasoning in court cases, showing how the central arguments can be modelled using argumentation schemes. The schemes used to model these kinds of arguments are comparable to the schemes used in Walton et al. (2008) to represent the same (or closely comparable) species of arguments so often used in everyday conversational discussions and deliberations. Recent research on legal argumentation in artificial intelligence shows how those modelling legal reasoning started with the argumentation schemes for everyday conversational reasoning, and applied them to legal argumentation. When integrating them with technology already used in argument interchange and law, for example case-based reasoning, it was found that the original schemes needed modification in order to be adapted for use in the legal context.

\section{Survey of recent literature on scheme classification}

The history of scheme classification has already been covered in Walton et al. (2008), but there have been more recent attempts surveyed in this section. We begin with some more theoretical ones to those that are more engaged with the practical task of building evidential indicators and criteria that can be used to identify real instances of argument in natural language discourse by fitting them to schemes.

Kienpointner's (1992) taxonomy is based on three distinctions. The first is the descriptivenormative distinction. The second is the real-fictitious distinction, where fictitious propositions are indicated by their expression in the subjunctive mode. The third is the pro-contra distinction, contrasting arguments that support a claim with those that attack a claim.

Warnick and Kline (1992) contend that a substantial set of identifiable attributes for each argumentation scheme can be extracted from the account of schemes given by Perelman and Olbrechts-Tyteca, in their book, The new rhetoric (1969). Perelman and Olbrechts-Tyteca (1969) classify schemes into four groups, quasi-logical, based on reality, establishing reality and dissociative. On the account given by Warnick and Kline (1992), schemes can be classified under these four categories. The first category is called quasi-logical arguments, because these schemes have the appearance of formal logic. They include transitivity arguments and arguments based on syllogisms. Also included under this heading are arguments from the rule of justice, that is, arguments that beings in the same categories should be treated in the same way. The second category, arguments based on the structure of reality, comprises arguments that rely on connections recognised by the audience. This category includes causal arguments, for example. A third general category is that of arguments establishing the structure of reality. These are arguments that call upon existing audience predispositions to create new audience perceptions. An example of a scheme falling into this category would be argument from example, which seeks to establish a new principle by referring to a particular case. Argument from analogy is also taken to fit into this category. Schemes in the fourth category, dissociation, modify a notion's conceptual structure by disengaging incompatible notions that had originally been unified (Warnick \& Kline, 1992, p. 7). The aim of this type of argument is to remodel an audience's concept of reality by resolving incompatibilities.

In addition to extracting this general categorisation of different kinds of uses of schemes from The new rhetoric, Warnick and Kline (1992, p. 8) also used it to estimate the reliability of the 
classification system they had found by identifying argumentation schemes in natural language discussions containing examples of arguments. This research is very interesting in that it makes the seminal writings of Perelman and Olbrechts-Tyteca more applicable to empirical research by trying to clarify and systematise their work on argumentation. However, it seems that the classification is still a general and abstract theory that represents different ways schemes can be used for argumentative purposes. It still remains to be seen how it could be developed into a more applicable approach that could help argument coders to classify any set of existing schemes in order to make them more easily applicable to the task of identifying kinds of arguments used in a natural language text of discourse.

Lumer and Dove (2011) use an epistemological approach to the classification of schemes based on epistemological principles. On their account, the most basic epistemological principles in the different argument types represented by schemes are deductive, probabilistic, and practical. Deductive argumentation schemes guarantee the truth of the conclusion of an argument, given that the premises are true. Probabilistic argumentation schemes use the axioms and theorems of the probability calculus and include projective statistical arguments, arguments from sign, knowledge-based arguments, and arguments to the best explanation used for purposes of interpretation (Lumer \& Dove, 2011, pp. 22-23). Practical argumentation schemes systematise arguments for personal prudential value judgements to guide actions. They include practical arguments for evaluations under uncertainty, practical arguments for evaluations under risk, practical arguments for justification of actions, and practical arguments for definitions (Lumer \& Dove, 2011, pp. 24-25).

Rahwan, Banihashemi, Reed, Walton, and Abdallah (2011) present a description logic ontology for annotating arguments based on the Argument Interchange Format, a system that aims to facilitate the exchange of semi-structured arguments between argumentation support tools like Araucaria, Truthmapping, Parmenides, and Carneades. Rahwan et al. (2011, p. 41) identify the set of schemes in Walton (1996) as the one that has been most influential in computational work, and so they use this scheme set, of which the one in Walton et al. (2008) is an extension, as the target of their classification system. Their hypothesis (Rahwan et al., 2011, p. 42) is that these schemes have a hierarchical ontological structure based on the classification of their constituent premises and conclusions. Their system works by showing how the premises in some simpler schemes are also contained in some more complex schemes. For example (Rahwan et al., 2011, p. 49), they show how the scheme for argument from negative consequences is a more general scheme into which the scheme for fear appeal argument fits as a special subtype. Essentially, the reason is that the statement that there will be negative consequences of a particular action being considered (characteristic of argument from negative consequences) is included as one particular premise in the structure of the fear appeal argument. Using this evidence, the fear appeal argument scheme can be classified as a sub-scheme of the scheme for argument from negative consequences, which represents the more general scheme of the two, in effect forming a cluster of schemes. Rahwan et al. (2011) also have a number of useful observations to make about how the critical questions matching a scheme can form a general inference pattern that links a scheme to a superclass of schemes that is more general. However, it needs to be noted that the aim of this research (Rahwan et al., 2011, 56) was not to present a complete classification system for argumentation schemes, but rather to show how some new kinds of automated reasoning systems using schemes are made possible by semantic web technologies. Nevertheless, the research of Rahwan et al. (2011) does offer criteria that can be used to show how some schemes can be classified as sub-schemes of others.

Feng and Hirst (2011) have the aim of developing what they call an argumentation scheme classification system with the ultimate goal of reconstructing enthymemes, arguments that have an unstated assumption as an unexpressed premise or conclusion. As an annotated corpus, they 
use the Araucaria database, an online repository of arguments including approximately 660 manually annotated arguments from sources like newspapers and court cases. They use the set of 65 argumentation schemes from Walton et al. (2008) and focus on the five schemes that are the most commonly used ones: argument from example, argument from cause to effect, practical reasoning, argument from consequences, and argument from verbal classification (Feng \& Hirst, 2011, p. 988). Their experimental data set was composed only of arguments annotated in accordance with the Walton scheme set in Araucaria. By their count the number of occurrences of the most common five schemes in the Walton scheme set constituted $61 \%$ of the total occurrences.

The evidential features that they used to identify an argument in a given text as fitting a particular scheme are called scheme-specific features (Feng \& Hirst, 2011, p. 990). These are selected cue phrases and patterns believed to be indicative of each scheme, and consist of keywords or phrases found in the text that are characteristic of a particular scheme. The scheme for practical reasoning has 28 keywords and phrases including 'want', 'aim', 'objective', and the four modal verbs 'should', 'could', 'must', and 'need' (Feng \& Hirst, 2011, p. 991). The scheme for argument from example has eight keywords and phrases including 'for example', 'such as', 'for instance', and so forth (p. 991). In the case of argument from consequences, the arguer is evaluating good and bad consequences of some course of action being considered, and therefore what Feng and Hirst (2011, p. 992) call 'sentiment orientation' is taken to be a good indicator for this scheme. Sentiment orientation would appear to be similar to the positive or negative use of emotively loaded language, like the words 'good' and 'bad' or 'hurrah' and 'boo'.

When they use the term 'classification', it appears that their goal, or at least their immediate goal, is not to produce a classification of the Walton scheme set by producing a classification tree in which some schemes would be classified under others. Rather it seems that the goal of their research is to build a method of identifying types of arguments in a natural language text or corpus of examples that fits some argumentation scheme that is a known structure representing a type of argument. We would be inclined to call this task argument identification rather than argument scheme classification. However, these two research goals are closely connected.

Bex and Reed (2011) build a system in which schemes can be classified into three broad categories they call schemes of inference, schemes of conflict, and schemes of preference. Schemes of inference can be modelled as conditional generalisations in either of two ways. One way is by connecting the antecedent of the conditional to the conclusion by way of a defeasible modus ponens inference. The other way is to represent the generalisation as a defeasible argumentation scheme. For example, the scheme for argument from witness testimony can be modelled as a defeasible modus ponens inference or as a metalinguistic inference rule in a rule-based system. Modelled either way, the basic structure of an argumentation scheme is that of an inference from a set of statements that fit into the scheme as its premises to another statement that fits into the scheme as its conclusion. Seen in either of these ways, the scheme has an inferential structure expressing a transition from a set of statements to another statement that is drawn from the prior set of statements.

Schemes of conflict, on the other hand, are based on a notion of logical conflict characterised by negation or contradiction between two statements. The basic concept in the scheme of conflict is that of attack, representing the idea that one argument is a counterargument to another that is aimed at the other argument to try to defeat it (Bex \& Reed, 2011, p. 11). However, conflict is not the same as attack. The notion of attack, in their view, is based on the prior notion of conflict. Conflict schemes, like inference schemes are often used in argumentation, are often expressed by generalisations, and represent abstract logical patterns of reasoning that can be strict or defeasible. An example of such a defeasible generalisation is the statement that two people cannot be in one place at the same time (Bex \& Reed, 2011, p. 12). While inference schemes allow us to build arguments, conflict schemes allow us to provide counterarguments to them. The scheme for the 
ad hominem argument might be a suitable example of a conflict scheme. This scheme is defined in such a way that it must represent a type of argument that was directed against a prior argument by attacking the character for trustworthiness of the arguer who put forward the prior argument. In other words, the ad hominem type of argument is inherently an attack argument on another argument, and hence should be classified as a conflict scheme. In contrast, the argument from expert opinion is put forward to support a claim that is the conclusion of the argument from expert opinion. Therefore, the argument from expert opinion should not be classified as a conflict scheme that has to be used to attack some other argument. It could be used in this way in some examples of its deployment in a discussion, but it does not have to be.

The third type of scheme is of the preference scheme. While inference and conflict schemes allow us to build arguments and provide counterarguments, preference schemes allow us to decide which arguments to accept when a choice needs to be made on which argument is preferable to accept. Like inference and conflict schemes, preference schemes can be based on generalisations. Bex and Reed (2011, p. 16) use the example of the generalisation that policies that promote equality are preferred to those that promote enterprise. Suppose we have to make a decision whether to lower or raise taxes, and we know that lowering taxes promotes enterprise while raising taxes promotes equality. On the basis of this generalisation, that expresses a preference for equality, we can draw the conclusion that the right choice is to raise taxes.

In a recent study of argumentation schemes in political argumentation, Hansen and Walton (2013) used schemes to classify kinds of arguments put forward by candidates in a provincial election in Ontario. One aim of the study was to find out which kinds of arguments are most commonly used in election campaigns by finding arguments matching a given list of schemes and trying to identify any new kinds of arguments not found on this list. The list, basically representing the schemes found in the textbook (Walton, 2006), consisted of the following 14 schemes and a category of 'none of the above':

1. Argument from position to know; 2. argument from expert opinion; 3. argument from popular opinion; 4. argument from commitment; 5. argument from ignorance; 6. circumstantial ad hominem argument; 7. abusive ad hominem argument; 8. argument from correlation to cause; 9. argument from positive consequences; 10. argument from negative consequences; 11. slippery slope argument; 12. argument from analogy; 13. argument from sign; 14. argument from (verbal) classification; 15. none of the above.

The six participants in the study tried to classify each argument collected as fitting one or another of these schemes. After it was found that over one-third of the arguments collected did not fit any of the 14 schemes, the original list was supplemented with some other schemes (e.g. the practical reasoning scheme), and two new schemes were proposed. One was a scheme for the argument from fairness (justice). This kind of argument was used when an opponent's argument or policy was criticised as unfair. The other was called the argument from misplaced priorities, identified in cases where one party accused the other of basing its position or argument on a set of priorities that is the reverse of the proper ordering of these priorities. These findings can be found in Hansen and Walton (2013).

\section{Ways and desiderata for classifying schemes}

Five ways of classifying schemes can be considered. The first way is that of classifying schemes according to premise dependency. For example, the scheme for argument from expert opinion depends on the assumption that an expert is in a position to know about some domain of expertise. Therefore since the argument from expert opinion depends on the argument from position to know in this way, argument from expert opinion can be classified as a species of argument from 
position to know. Another example is the circumstantial ad hominem argument, which has one premise to the effect that the arguer being attacked is committed to an inconsistency. Thus a part of the circumstantial ad hominem scheme is an argument from inconsistent commitments, a type of argument that has its own distinctive scheme. Because the circumstantial ad hominem scheme depends on the scheme for argument for inconsistent commitments in this way, we can say that the former scheme is a species of the latter. Another example would be the scheme for the relationship between the causal slippery slope argument and in the scheme for the argument from negative consequences. The causal slippery slope argument can be classified as a species of argument from negative consequences because one of its premises makes the claim that if the arguer takes a course of action being considered, there will be negative consequences of taking that course of action.

The second way is to classify schemes according to general category. For example, some of the schemes are instances of epistemic reasoning and are about knowledge. Therefore the scheme for argument from ignorance, because it is a form of argument from lack of knowledge, can be said to fall under this general category of knowledge-based schemes, forming a cluster Another example is the scheme for the ad hominem argument, which has several subcategories, but all of them have the common element that they are personal attack arguments. This common characteristic of being personal attack arguments can therefore be used to classify ad hominem arguments as a distinct species of argumentation. But they also fall under the more general category of source-based arguments (Macagno, 2013). Still other schemes involve applying general rules to specific cases. This type of argument is prominent in law, for example. There could also be a third broad category of schemes that do not fall into these two, and that are more minimal, in that they are more about the reasoning in an argument rather than about the source or rules.

The third way is to classify schemes in relation to the nature of the conclusion of the scheme (Macagno, 2015; Macagno \& Walton, 2015). For example, epistemic schemes might be contrasted with deliberative schemes. The conclusion of an epistemic scheme is that a particular proposition is known to be true or known to be false, whereas the conclusion of the deliberative scheme is that a particular action should be carried out or not carried out.

The fourth way is to classify schemes according to their conclusive strength. For example, deductive schemes could be taken to be the strongest, while inductive schemes are taken to be weaker in their conclusive strength, and the defeasible schemes that fit neither deductive nor inductive criteria are taken to be the weakest. There could be a classification of deductive schemes, and inductive schemes, and some third category possibly called conductive schemes (Govier, 1992), that represent defeasible kinds of arguments that are neither deductive nor inductive. There are several problems with this way of classifying schemes. One is that, so far, there is very little theoretical agreement on how to define the third category, and how to clearly separate it from the first two categories. Another is that some of the schemes can fall into both categories. Consider argument from expert opinion as an example. Assuming an expert or database is taken as all the facts in a given domain of knowledge, it can be argued that argument from expert opinion should be seen as a form of argument that is deductively valid. If the degree of expertise of the expert or database can be quantified numerically, based on a track record or some other measurable factor, argument from expert opinion the scheme could be seen as an inductive form of argument. In the most common instances of argument from expert opinion in both law and everyday conversational argument, however, neither of these assumptions can be fulfilled. So perhaps one could argue that scheme for argument from expert opinion should go into the third category. But in some instances, even though they may be rare, it would be unjustifiable to place it unqualifiedly in the third category. There are other problems as well. Putting it in the first category of deductively valid arguments is to treat the expert source is omniscient, a way of treating arguments from expert opinions that is associated with the fallacy of appeal to authority. 
The fifth way is to classify schemes according to dialectical function, referring to the purpose an arguer has in bringing forward an argument in a discussion or debate. For example, some arguments are mainly used in a positive way to support one's own view, while in other instances an argument is used to criticise an opponent's position or argument. Also, still other arguments are typically used for the purpose of criticising the person who holds a view or takes a position. This kind of use of argument can be described as having a personal function. We could take the ad hominem argument as a case in point (Walton, 1998). It is defined as the use of character attack to attack another party's argument by attacking the other party's character, specifically, by using that attack to try to undermine the credibility of the other party. Essentially, the ad hominem argument is used to attack the trustworthiness of one's opponent as a participant in the discussion of the kind that needs to depend on trust (Macagno, 2013).

The literature on classification of argumentation schemes is still very new, and so it seems hard to know the best way to proceed. In this paper, we will explore a way to classify schemes according to general category, and concentrate on arguments used in everyday conversation argumentation (even though many of these are the same as, or comparable to schemes used in legal argumentation). A new classification of the second type is to put forward as basis for exploration so that specific problems with applying it can be studied. This approach will provide a way to move forward to gaining an insight into the general project of classifying schemes. This tentative system classifies schemes under four categories, 'discovery arguments', 'practical reasoning', 'source-based arguments', and 'applying rules to cases', so in the next four sections we provide examples of schemes falling under each category. It seems best to begin with the kinds of arguments that appear to be most commonly used in everyday conversational argumentation, and then go from there to see whether these are also used in legal argumentation, or whether legal argumentation needs special schemes, and special systems for classification of those schemes.

The desiderata for building a classification system of schemes meant to be applicable to argumentation in everyday conversational discourse should be the following:

(1) A classification system should be helpful to users for the task of attempting to identify whether a given argument in a text of discourse fits a particular scheme or not.

(2) A classification system should be able to help users deal with what are taken to be the most common arguments of the kind that appear in everyday conversational discourse.

(3) Where there are borderline cases where a given argument fits or appears to fit more than one scheme, there should be additional criteria stated that enable the user to have an evidential basis for classifying the argument as fitting one scheme rather than another.

(4) A classification system should pick out some general feature common to all groups of schemes that are closely related to each other, and use it to group the schemes together.

(5) A classification system should not be more complex than users will find helpful.

(6) A classification system may have different ways of grouping different types of schemes together where these differences result in a classification that is more useful.

The primary use of the classification system is to increase the understanding of an argument analyst, let us say a student in a course on argumentation, to be able to situate an argument in relation to other arguments it is related to, so that the student can carry out the task of fitting the right scheme to a given text of discourse assumed to represent an argument. The secondary use of the classification system is to help computational systems of argument mining build computational tools for the same purpose, except that they might be applied to particular contexts of argumentation use such as law. The third use of the classification system is to offer resources to help the application of argumentation schemes to the analysis and modelling of legal argumentation of various kinds. 


\section{Schemes for source-based arguments}

The ancient dialectical accounts (see Cicero, Topica and Boethius, De Topicis Differentiis) distinguished between two types of sources of the strength of an argument, namely intrinsic and extrinsic sources. The first one refers to the relationship between the subject matter (or the linguistic features thereof) and the reasoning. The second one concerns the support provided by the credibility of who provides the opinion supporting the conclusion. In this case, it is not the subject matter that is used to bear out the conclusion, but rather an external authoritative voice. We refer to these arguments as 'source-based'. In everyday English, a source can also be a book or other forms of evidence, and we use the term 'source-based' to include human agents as well as written sources, pronouncements of experts, and other forms of evidence of this kind.

Here is a typical example of argument from position to know. If one is trying to find the best way to get to City Hall in an unfamiliar city, it may be helpful to ask a passer-by. If it looks like this passer-by is familiar with the city, and she says that City Hall is two blocks east, it could be reasonable to accept the conclusion that City Hall is two blocks east. This form of reasoning is called position to know argumentation.

Where $a$ is a source of information, the following argumentation scheme (Walton et al., 2008, p. 309) represents position to know argumentation.

Major Premise: Source $a$ is in position to know about things in a subject domain $S$ containing proposition $A$.

Minor Premise: $a$ asserts that $A$ is true (false).

Conclusion: $A$ is true (false).

Such an argument can be reasonable in many instances, but it also defeasible. It can be critically questioned by raising doubts about the truth of either premise, or by asking whether $a$ is an honest (trustworthy) source of information.

Let us consider once again the case of asking the passer-by where City Hall is located in a city one is not familiar with. Such a case is clearly an instance of position to know reasoning, but is it also an instance of the scheme for argument from expert opinion? Argument from expert opinion is a subspecies of position to know reasoning, based on the applicability of the assumption that the source is in a position to know because she is an expert. Students in a critical thinking course are often inclined to think so, because it may seem to them reasonable to say that the passer-by is being consulted as an expert on the city streets. After all, if she is very familiar with them, she might be said to have a kind of expert knowledge of them.

The argumentation scheme for argument from expert opinion described in Section 4 is different from the one for argument from position to know, because it is required that the source who is in a position to know be an expert. For example, ballistics experts and DNA experts are often used to give expert testimony as evidence in trials, but they must qualify as experts. It is rarely wise to treat an expert as infallible, and taking that approach is the source of the fallacious argument from expert opinion. In most typical cases, it should be treated as a form of argumentation that is presumptively plausible but defeasible, and open to critical questioning.

On this interpretation, the argument would fit the major premise of the scheme for argument from expert opinion (Section 4). But in the absence of further evidence, can it be correctly said that she is an expert? Unless she is a cartographer, or an expert on city planning, or has some qualification of that sort, she would probably not qualify as an expert in the sense in which the term is used in law. In short, we can draw a distinction between having a working or practical knowledge of some area, and having expert knowledge of it. At any rate, this seems to be the basis of the distinction between the two schemes.

The basic scheme for the ad hominem is that for the direct type (Walton, 1998, p. 249). 
PREMise: $a$ is a person of bad character.

CONCLUSION: $a$ 's argument should not be accepted.

The proponent $a$ attacks the respondent's argument by arguing that he is a person of bad character and for that reason his argument should be rejected. The basis of this kind of attack is the assumption a person's argument should depend on his ethical character, especially for honesty and trustworthiness to tell the truth. This simple type of argument is often called the abusive ad hominem argument in logic textbooks, a negative term suggesting that all ad hominem arguments are fallacious. In fact, they are often reasonable, as in a case where the trustworthiness of a witness is attacked during cross-examination in court.

The circumstantial ad hominem argument combines the scheme for the direct ad hominem argument with the scheme for argument from inconsistent commitment (Walton, 2006, p. 123). The latter type of argument, a species of argument from commitment, has the following argumentation scheme (Walton, 1998, p. 252).

Initial Commitment Premise: $a$ has claimed or indicated that he is committed to proposition $A$ (generally, or in virtue of what he said in the past).

Opposed Commitment Premise: other evidence in this particular case shows that $a$ is not really committed to $A$.

CONCLUSION: $a$ 's commitments are inconsistent.

Argument from inconsistent commitment is also a defeasible form of argument that can be cast into doubt by asking critical questions that delve into the textual details of the given case to judge whether the alleged inconsistency can be proved to be real, based on the arguer's commitments. For even if the arguer being attacked admits there really is an inconsistency of the alleged sort in his commitment set, he might still be able to explain how the conflict can be dealt with and resolved. He may have simply changed his mind on the basis of new evidence he was not previously aware of.

What follows is the argumentation scheme for the circumstantial ad hominem argument (Walton, 1998, p. 253).

Argument Premise: $a$ advocates argument $\alpha$, which has proposition $A$ as its conclusion.

Inconsistent Commitment Premise: $a$ is personally committed to the opposite (negation) of $A$, as shown by commitments expressed in her/his personal actions or personal circumstances expressing such commitments.

Credibility Questioning Premise: $a$ 's credibility as a sincere person who believes in his own argument has been put into question (by the two premises above).

Conclusion: The plausibility $a$ 's argument $\alpha$ is decreased or destroyed.

It is important here to distinguish between an argument from inconsistent commitment that is not an ad hominem argument and one that is. Only the latter should properly be classified as an ad hominem argument, according to the analysis defended at some length in Walton (1998). Throughout the long history of the subject (Walton, 1998, pp. 106-111) argumentum ad hominem has often been assumed to be identical to argument from inconsistent commitment. However, according to Walton (1998), all ad hominem arguments, including the circumstantial type, should be classified as species of personal attack arguments. This classification rests on the assumption that all genuine ad hominem arguments should contain an attack on the arguer's ethical character. In the scheme for the circumstantial ad hominem argument above, that requirement of the credibility questioning premise makes the scheme meet this requirement. 
Schemes are increasingly being recognised, applied, and studied in computational domains like artificial intelligence and multi-agent systems, and are being used to improve the reasoning capabilities of artificial agents. Schemes are being incorporated into software tools for argument mapping, like Araucaria ${ }^{1}$ and Carneades. ${ }^{2}$ Araucaria aids a user to construct a diagram of the structure of an argument by pasting the text of the argument in and then by connecting all the premises and conclusions in an argument map. A user can also select argumentation schemes from a menu and use them as part of the process of analysing and evaluating the argument. Carneades also makes argument maps, but can apply schemes to argument construction (invention) as well as to argument analysis and evaluation (Gordon \& Walton, 2009b).

An example argument from Newsweek (22 November, 2010, p. 7) can be used to illustrate argument reconstruction involving schemes. The text is quoted as follows:

Dmitry Medvedev has made his name talking up liberal ideas and blasting corrupt bureaucrats. But when his nation's pride is at stake, Russia's president sounds like his hard-nosed mentor, Prime Minister Vladimir Putin. As Medvedev revealed last week that the 10 Russian spies arrested in the U.S. last June were betrayed by a mole inside Russia's Foreign Intelligence Service, and that the turncoat had since fled to America, the usually mild-mannered president added with relish that a 'Mercader' had already been sent to deal with the traitor - a chilling reference to Ramon Mercader, the secret agent sent by Joseph Stalin to kill archrival Leon Trotsky with an ice pick. The arrest of the sleeper agents and the defection of their boss is the 'biggest failure of Russian intelligence in 90 years,' says Gennady Gudkov, a former KGB colonel who now heads the Russian Parliament's Security Committee. 'It shows that our spies are losing their ideals.' No wonder Medvedev is peeved. Still, ordering a murder on U.S. soil seems out of line with Russia and America's new 'reset' relations. In aping the Soviet era's brutal methods, Medvedev could be losing his own ideals.

To provide reconstruction of the central argument in this example, we start with a key list of seven statements that are either made or clearly implied in the text.

(1) M made his name talking up liberal ideas.

(2) $\mathrm{M}$ has claimed that he is committed to liberal ideas.

(3) $\mathrm{M}$ ordered the murder of a spy.

(4) Ordering the murder of a spy is an action that is not consistent with liberal ideas.

(5) This evidence shows that $\mathrm{M}$ is not really committed to liberal ideas.

(6) M's commitments are inconsistent.

(7) M could be losing his own ideals.

The visualisation of the example shown in Figure 1 conforms to the format of Araucaria, a well-known argument visualisation tool.

The ultimate conclusion of the argument is taken to be the statement in the text box at the top claiming that $\mathrm{M}$ could be losing his ideals. According to the analysis shown in Figure 1, the arguments supporting this conclusion are based on the scheme for argument from inconsistent commitment. The shaded areas shown around the selected arrows and text boxes represent the portion of the argument to which the scheme applies. The other statements shown below the selected argument are represented as premises of additional arguments supporting the premises of the argument from inconsistent commitment.

The argument shown in Figure 1 is not represented as a circumstantial ad hominem argument. There are several indications in the text quoted in the example above that $\mathrm{M}$ is being portrayed negatively as a bad person. It is claimed that he sounds like his hard-nosed mentor, that he is losing his ideals and that he has ordered a murder. The methods he has used are called brutal. This could be evidence for reconstructing the argument as the circumstantial ad hominem argument rather than merely as an argument from inconsistent commitment. However, the central thrust of the argument does not seem to be a personal attack on $\mathrm{M}$. The central focus of the argument is 


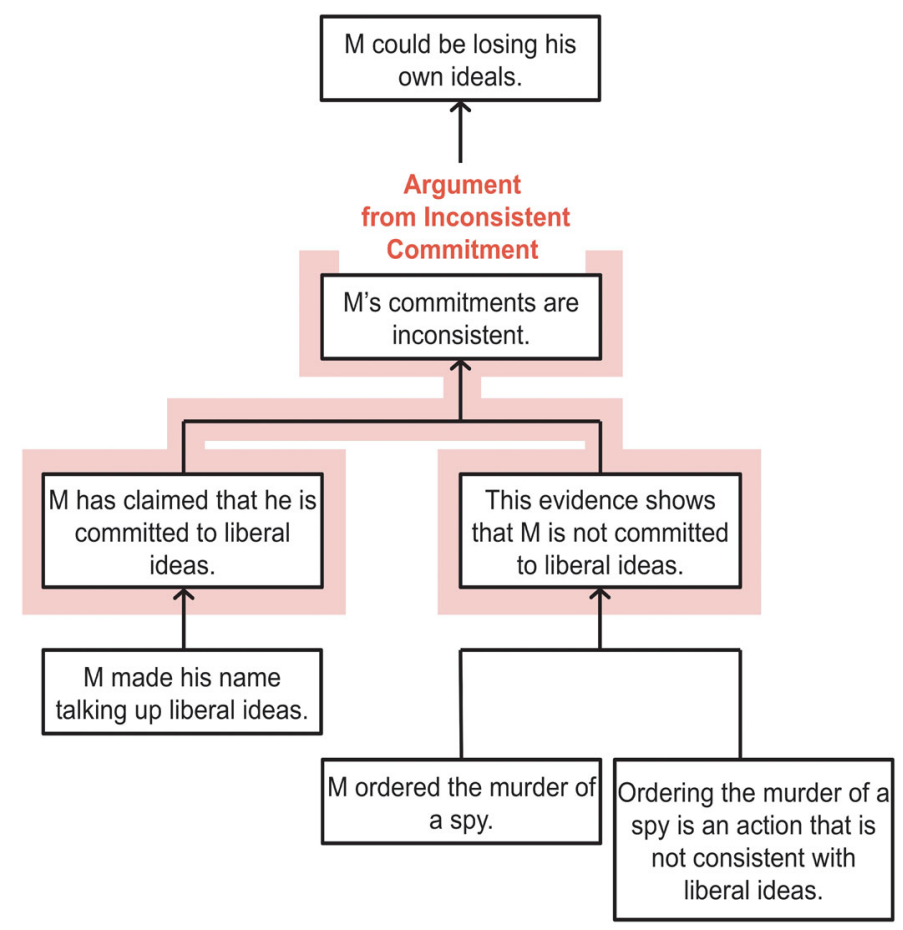

Figure 1. The $\mathrm{M}$ argument visualised using araucaria.

on presenting evidence to show the inconsistency between his action and what are taken to be his liberal ideas.

\section{Schemes for practical reasoning}

The internal sources of arguments can be divided according to two criteria: the nature of the generalisation linking premises and conclusion, and the relationship between the generalisation and the premises. The first distinction concerns the difference between practical arguments and epistemic (theoretical) arguments. Arguments of the first type are grounded on generalisations concerning the desirability of a state of affairs, which leads to a decision or a proposal to act (Westberg, 2002, p. 85). In practical reasoning, often called goal-directed reasoning, an agent or group of agents makes a decision to carry out an action based on goals that have been identified, taking into account possibly contravening factors like negative side effects of the proposed action (Atkinson \& Bench-Capon, 2007). The SC argument is a case in point.

The SC argument can be illustrated by the example of the Ph.D. student who has been working on her Ph.D. thesis for a long time, and despairs of ever finishing it. As an alternative, she thinks of the idea of going to law school. The big advantage of that alternative is that she will graduate after a definite period of time. But then she reasons to herself using the following argument: if I drop out of the Ph.D. program now, all those years of hard work will be wasted. That would be a great pity, so I think I had better resist the idea of applying for law school. The argumentation scheme representing this form of argument is called argument from waste (Walton, 1996, p. 80), where $a$ is an agent, and $A$ is a statement that represents the outcome of an action.

PREMISE: If $a$ stops trying to realize $A$ now, all $a$ 's previous efforts to realize $A$ will be wasted. 


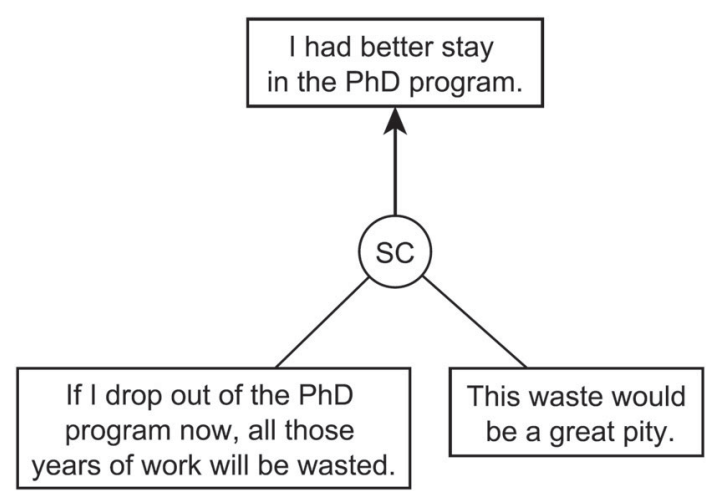

Figure 2. Argument diagram of the SC argument.

Premise: If all $a$ 's previous attempts to realize $A$ are wasted, that would be a bad thing.

Conclusion: Therefore, $a$ ought to continue trying to realize $A$.

Argument from waste seems to be either the same as, or very similar to a form of argument known in business and financial decision-making as the SC argument.

Figure 2 presents an argument representing a small part of the example above about the Ph.D. student. The argument configuration shown is that of a linked argument in which the two premises fit together to support the conclusion. The reason they fit together is that they are both required premises in the argumentation scheme for the SC argument. The name of the argumentation scheme for the SC argument is indicated on the arrow representing the inference from the two premises to the conclusion.

The argumentation scheme for the SC argument is based on a notion of revising commitment over time. The proponent of the argument commits herself to an action at time $t_{1}$, represented as statement $A$. At a later time $t_{2}$, she is confronted with the decision of whether to carry out this pre-commitment to $A$ or not. The reason in favour of $A$ would be the following argument: I am already committed to $A$; therefore, I should carry out $A$. The Ph.D. student in the example might reason as follows. I am already committed to the policy of working on my thesis because I have already sunk so much time and work into it. Therefore, I should keep working on my thesis and resist the temptation to apply for law school.

The argumentation scheme for the argument from SC can now be represented as follows.

Premise: There is a choice at $t_{2}$ between $A$ and not-A.

Premise: At $t_{2}$ I am precommitted to $A$ because of what committed myself to at $t_{l}$.

ConClusion: I should choose $A$.

The example of the Ph.D. student has arguments on both sides, and thus it represents the typical case of argumentation directed towards resolving a conflict of opinions. The two sides of the argument are represented in Figure 3. The scheme for argument from SC is shown in the argument on the left side and the scheme for argument from positive values (PV) is shown in the argument on the right side, respectively.

The argument from SC shown on the left side is a species of argument from commitment, but there is an opposed argument from PV represented on the right side of Figure 3. The double arrow represents this opposition. Both arguments might be evaluated in a traditional approach by using cost-benefit analysis to examine the costs and benefits on each side. However, the argumentation approach is different. It proceeds by constructing an argument diagram representing the chain 


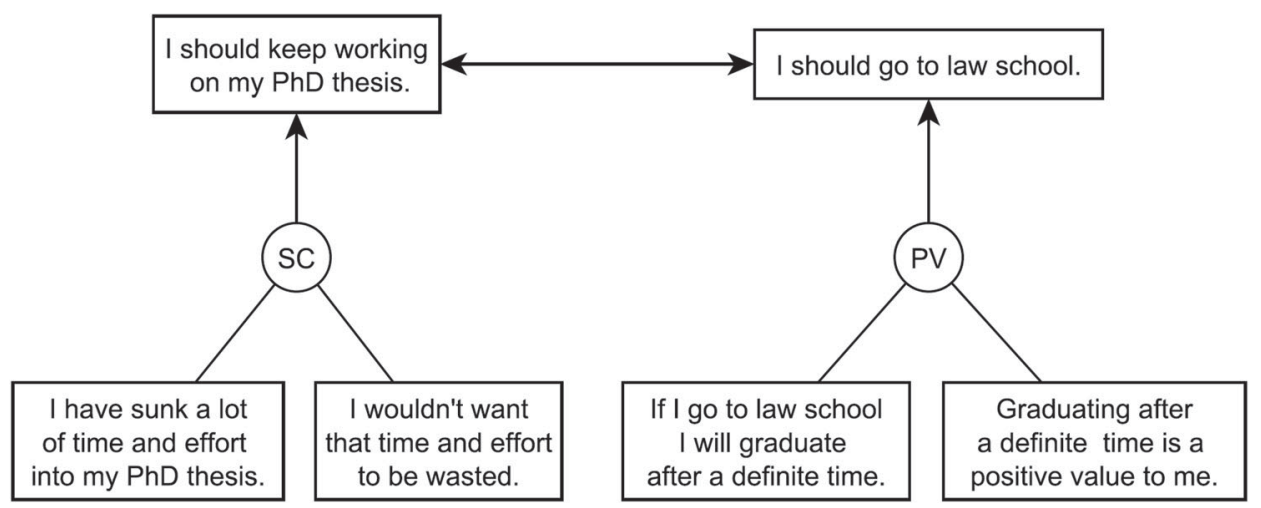

Figure 3. Two sides of the argument.

of argumentation on each side of the disputed issue, including the argumentation schemes representing each component argument. It then weighs up the strength of the chain of argumentation on each side, sets the standard of proof representing how much stronger each side's argument needs to be in order to win, and decides the outcome on this basis. It uses argumentation schemes like practical reasoning, argument from positive and negative consequences, and argument from positive and negative values, schemes to be explained later in this paper that are closely related to SC arguments.

The argumentation scheme for the argument from SC can be classified as a species of argument from commitment. In the example of argument from commitment in Walton (1996, p. 55), George goes around saying 'Power to the people'. And often declares that Marx and Lenin are his heroes. It would be reasonable to infer from this evidence on the basis of argument from commitment that George is committed to communism. This form of argument is defeasible. George might change his mind and recant his communist views after the fall of the Soviet Union. If someone goes on record as asserting a statement, based on argument from commitment we can infer from his statement that he is committed to it. The following argumentation scheme for argument from commitment is from Walton (1996, p. 56).

Premise: $a$ is committed to proposition $A$ (generally, or in virtue of what she said in the past).

ConCLusion: In this case, $a$ should support $A$.

This form of argument is very common in everyday conversational argumentation, and a common problem with it is that commitments sometimes need to be retracted after they have been incurred (Hamblin, 1970; Walton \& Krabbe, 1995).

Argument from SC is a species of argument from commitment. However, since argument from $\mathrm{SC}$ is about actions and choices between alternative actions, it also fits naturally into the form of argumentation called practical reasoning (Walton, 1996, pp. 11-13). This form of reasoning is goal-directed and commitment-based. In argument from SC, an agent is typically committed to some course of action because it is a goal of hers, and because she has invested resources of time and effort, and perhaps money, into trying to realise this goal. As a worthy goal, and one that costs have been sunk into, this policy or outcome represents a commitment for the agent. According to the practical reasoning model, the inference proceeds from a goal to a means to realise that goal (Walton, 1990). If $A$ is the agent's goal, and to bring about $A$, it looks to her like she should bring about $B$, then she draws the conclusion that she should bring about $B$. For example, finishing her thesis is her goal. To finish her thesis, it looks to her like she needs to keep working on it. By practical reasoning then, she draws the conclusion that she should keep working on her thesis. As 
this example shows, the SC argument makes sense once it is fitted into the scheme for practical reasoning.

In the scheme for practical reasoning below, the first-person pronoun ' $\mathrm{I}$ ' represents a rational agent who has goals, some (though possibly incomplete) knowledge of his/her circumstances, the capability of changing those circumstances and some awareness of the consequences of his/her actions (Walton et al., 2008, p. 323).

Major Premise: I have a goal $G$.

Minor Premise: Carrying out this action $A$ is a means to realize $G$.

ConCLusion: Therefore, I ought (practically speaking) to carry out this action $A$.

One of the critical questions matching the scheme is the side effects question: what consequences of my bringing about $A$ should also be taken into account? (Walton et al., 2008, p. 323). Asking this critical question can cast an argument based on practical reasoning into doubt. This purely instrumental scheme for practical reasoning does not take into account the values that a goal might be based on.

In addition to the purely instrumental scheme for practical reasoning, there is also a valuebased variant described below in a five-line format, where the second line expresses the conclusion of the argument (Greenwood, Bench-Capon, \& McBurney, 2003).

In the circumstances $R$

we should perform action $A$

to achieve new circumstances $S$

which will realize some goal $G$

which will promote some value $V$.

Matching this scheme for value-based practical reasoning is a set of 16 critical questions identified in Atkinson, Bench-Capon, and McBurney (2005, p. 858).

The value-based scheme for practical reasoning (Atkinson et al., 2005; Bench-Capon, 2003) can be classified as a composite made up of two other similar schemes, namely the instrumental scheme for practical reasoning and another scheme called argument from values. Argument from values has two subtypes, argument from PV and argument from negative value.

The scheme for argument from PV (Walton et al., 2008, p. 321) has the following form.

Premise i: Value $V$ is positive as judged by agent $A$.

Premise 2: If $V$ is positive, it is a reason for $A$ to commit to goal $G$.

Conclusion: $V$ is a reason for $A$ to commit to goal $G$.

The scheme for argument from negative value (Walton et al., 2008, p. 321) has the following form.

Premise i: Value $V$ is negative as judged by agent $A$.

Premise 2: If $V$ is negative, it is a reason for retracting commitment to goal $G$.

Conclusion: $V$ is a reason for retracting commitment to goal $G$.

Note that value-based practical reasoning can be classified as a hybrid scheme that combines argument from values with practical reasoning.

Instead of merely asking a critical question in response to a practical reasoning that concludes in a proposed action argument, a critic could argue that there will be negative consequences 
of the action. The argumentation scheme representing this type of argument is called argument from negative consequences. However, this scheme also has a positive form, in which positive consequences of an action are argued to be reasons for carrying it out (Walton et al., 2008, p. 332 ), where $A$ represents a state that could be brought about by an agent. This scheme is called argument from positive consequences.

PREMISE: If $A$ is brought about, good consequences might occur.

ConCLusion: Therefore $A$ should be brought about.

The other form is called argument from negative consequences.

Premise: If $A$ is brought about, then bad consequences might occur.

ConCLusion: $A$ should not be brought about.

An instance of either form of argument from consequences can be stronger or weaker, depending on the critical questions that have been asked or replied to.

What has been shown in this section is that the argument from SC is a hybrid scheme, a subspecies of both argument from commitment and practical reasoning, and can be best understood as a form of reasoning when embedded in the schemes for these other two types of argumentation. Argument from SC is a species of argument from commitment in which a sequence of deliberation is taking place between two choices and there is a time lapse between an earlier commitment and the time of the choice. At the same time, argument from SC is also a special form of practical reasoning involving an agent's deliberations about his or her goals and the means of carrying out these goals.

\section{Schemes for applying rules to cases}

Epistemic reasoning can be divided in two broad categories, depending on the relationship between the generalisation, the premises, and the conclusion. Arguments basically aimed at classifying entities or events under a general (implicit or explicit) rule, and drawing a particular conclusion therefrom, shall be distinguished from arguments aimed at establishing new rules, or retrieving properties or entities that are not contained in the general rule. We refer to the first group as 'schemes for applying rules to cases'.

In studying the question of how legislation and precedents are useful for the drawing of conclusions in law, Verheij (2008) summarised the basic forms of reasoning using two inference patterns. The first pattern is called Application of Legislation (Verheij, 2008, p. 22):

Major Premise: There is a rule with conditions $A, B, C, \ldots$ and conclusion $Z$.

Minor Premise: In the current case, the conditions $A, B, C, \ldots$ are fulfilled.

Conclusion: $Z$ can be drawn.

This rule says that if the conditions of a rule are fulfilled, the conclusion of the rule may be drawn (Verheij, 2008, p. 23). This inference pattern is similar to the following basic argumentation scheme for defeasible rules (Bench-Capon \& Prakken, 2010, p. 159):

Major Premise: if statements $P_{1}, P_{2}, \ldots, P_{n}$ apply, then statement $Q$ may be inferred.

Minor Premise: Statements $P_{1}, P_{2}, \ldots, P_{n}$ apply.

ConCLUSION: $Q$ may be inferred

Both of these similar inference patterns are related to the argumentation scheme called argument from an established rule. Both patterns are clearly meant to apply specifically in a legal 
setting, whereas the scheme for argument from an established rule is meant to apply to everyday conversational argumentation. The version of this latter scheme given in Walton et al. (2008, p. 343) is shown below.

MAJOR PREMISE: If carrying out types of actions including the state of affairs $A$ is the established rule for $x$, then (unless the case is an exception), $x$ must carry out $A$.

Minor Premise: Carrying out types of actions including the state of affairs $A$ is the established rule for $a$.

ConCLUSION: Therefore $a$ must carry out $A$.

In the common kind of case in legal reasoning where an established rule is applied to a particular case, say by a judge, the scheme for argument would take this form.

Major Premise: If rule $R$ applies to facts $F$ in case $C$, conclusion $A$ follows.

Minor Premise: Rule $R$ applies to facts $F$ in case $C$.

ConClusion: In case $C$, conclusion $A$ follows.

This scheme seems to represent the same type of argument as Verheij's application of legislation pattern and Bench-Capon and Prakken's basic argumentation scheme for applying a rule, even though the details of format are different.

The second pattern concerns the following of precedents, a pattern of reasoning that can take two forms in law, according to Verheij $(2008$, p. 23). One form is to treat the precedent as a rule. The other form of reasoning from precedent is called Analogical Following of a Precedent (Verheij, 2008, p. 23).

PREMISE: There is a precedent with $A, B, C, \ldots$ as factors relevant for conclusion $Z$.

PREMise: The current case matches the factors $A, B, C, \ldots$ of the precedent.

ConClusion: Conclusion $Z$ can be drawn.

According to this rule, if a case constitutes a precedent with a number of factors that match the current case, the conclusion of the precedent can be drawn.

Verheij's identification of these forms of reasoning has two especially important implications for the study of legal argumentation schemes. The first is that these inference patterns can be designated as representing fundamental argumentation schemes for legal reasoning. The first one fits the general argumentation scheme for argument from an established rule (Walton, 1996, p. 92), and can be seen as its legal version. The second inference pattern, Analogical Following of a Precedent, combines two schemes, the one for argument from analogy and the one for precedent. However, if you look at the scheme for argument from precedent in Walton (1996, p. 94), the match with Analogical Following of a Precedent is far from obvious. To make everything fit into place, several remarks are in order.

The first remark is that the scheme for argument from precedent given in Walton (1996, p. 94) does not represent the most common use of argument from precedent in law.

Premise: The existing rule says that for all $x$, if $x$ has property $F$ then $x$ has property $G$.

PREmise: But in this case $C, a$ has property $F$, but does not have property $G$.

Conclusion: The existing rule must be changed, qualified, or given up, or a new rule must be introduced to cover case $C$.

This scheme fits the kind of case where a precedent is found in a case on the grounds that the case is shown to be an exception to the given rule that would normally apply in that case. 
This scheme, however, does not apply to cases of argument from precedent of the kind used most characteristically in legal reasoning. This scheme applies to a kind of case in which there is an established rule, but an exception to it is found of the kind that requires modifying the rule by allowing the case at issue as representing a legitimate exception (Ashley, 2006). It could be applied to a case where there is a rule that vehicles are not allowed in the park, but where in the current instance, the vehicle is an ambulance. The drawing of the conclusion that the ambulance should be allowed in the park in this instance might lead to modification of the rule as follows: vehicles are not allowed in the park, except for ambulances.

The more characteristic type of argument from precedent used in legal reasoning applies to a different type of case. In this kind of case, there is a case at issue, and a prior case that has already been decided is taken as a precedent that can be applied to the present case. The argumentation scheme appropriate for this latter type of legal argumentation can be set up as follows.

Previous Case Premise: $C_{l}$ is a previously decided case.

Previous Ruling Premise: In case $C_{l}$, rule $R$ was applied and produced finding $F$.

New Case Premise: $C_{2}$ is a new case that has not yet been decided.

Similarity Premise: $C_{2}$ is similar to $C_{1}$ in relevant respects.

ConCLusion: Rule $R$ should be applied to $C_{2}$ and produce finding $F$.

It is the scheme above that should properly have the name of argument from precedent in legal reasoning. The scheme prior to the one above was called argument from precedent in Walton (1996, p. 94) and Walton et al. (2008, p. 344). It needs to be re-labelled, and called argument from an exception to the creation of a precedent.

Because of its similarity premise, argument from precedent is related to argument from analogy. Argument from analogy can be regarded as a form of reasoning from an implicit and inferred criterion of classification (Macagno \& Walton, 2009; Macagno, 2014; Macagno, Walton, \& Tindale, 2014). On this view, analogy at the same time leads to the creation of a new implicit classification criterion (a rule), and uses it to draw a conclusion. However, the rule is simply used, not explicitly stated. For this reason, this type of reasoning falls under the category of applying rules to cases. Argument from analogy has two basic forms. The first form has the following argumentation scheme (Walton et al., 2008, p. 315).

Similarity Premise: Generally, case $C_{1}$ is similar to case $C_{2}$.

Base Premise: $A$ is true (false) in case $C_{l}$.

Conclusion: $A$ is true (false) in case $C_{2}$.

One can see that argument from precedent is a subtype of this type of argument from analogy, the first form of argument from analogy.

The second type of argument from analogy (Guarini, 2004, p. 161; Macagno \& Walton, 2009) has to do with the classification of features of objects. The variables $a$ and $b$ stand for objects (individuals).

PREMISE: $a$ has features $f_{1}, f_{2}, \ldots, f_{n}$.

PREMise: $b$ has features $f_{1}, f_{2}, \ldots, f_{n}$.

ConCLusion: $a$ and $b$ should be treated in the same way with respect to $f_{1}, f_{2}, \ldots, f_{n}$.

This scheme is used in case-based reasoning to solve a problem posed in a given case by drawing on similar cases retrieved from a database of past cases. The solution to the problem matches 
a pair of cases by isolating features, specific respects in which one case is similar to or dissimilar to another (Juthe, 2005). Features are sometimes called factors, or sometimes dimensions, depending on which kind of case-based reasoning is being applied (Ashley, 2006).

\section{Discovery arguments}

The category of discovery arguments includes arguments aimed at establishing rules, such as the inductive arguments (called Argument from a Random Sample to a Population: from the observation of several instances of the co-existence of two properties a generalisation is concluded), the so-called abductive arguments, and the argument from ignorance.

Arguments that are grounded on the so-called abductive type of reasoning can be understood as belonging to a generic pattern, called argument from best explanation (Walton et al., 2008, p. 171):

$F$ is a finding or given set of facts.

$E$ is a satisfactory explanation of $F$.

No alternative explanation $E_{1} \ldots n$ given so far is as satisfactory as $E$.

Therefore, $E$ is plausible, as a hypothesis.

The argument from best explanation can lead to both a general rule (evidence to a hypothesis), or a specific conclusion (the attribution of a property to an individual). For this reason, this pattern is closely related to other two patterns: the argument from correlation to cause, and the argument from sign. The argument from correlation to cause is a shorter, heuristic pattern of reasoning that leads to a causal relation as an explanation of a correlation between two events (Walton et al., 2008, p. 328):

Premise: There is a positive correlation between $A$ and $B$.

Conclusion: Therefore, $A$ causes $B$.

Argument from sign, on the contrary, does not lead to a general rule, but rather to a particular (individual) conclusion, concerning a predication attributed to an individual. Also this pattern is a heuristic one, not directly taking into account the various possible explanations that can be advanced for an event. However, in case of assessment, such possible alternative explanations (rules) need to be taken into account and compared. The pattern can be represented as follows (Walton et al., 2008, p. 329):

Specific Premise: A (a finding) is true in this situation.

General Premise: $B$ is generally indicated as true when its sign, $A$, is true.

Conclusion: $B$ is true in this situation.

The last generic pattern of argument that belongs to this class is the argument from ignorance. Argument from ignorance (Macagno \& Walton, 2011), or argument from lack of evidence, as it might better be called, is another scheme that is so common and natural that we are generally unaware that we are using it. It is a common principle used in knowledge-based systems in computing, where it is called the closed-world assumption (Clark, 1978). The closed-world assumption is met if all the positive information in a database is listed, and therefore negative information is represented by default (Reiter, 1980, p. 69). For example, in a database for an airline flight schedule, if a flight connection between two cities is not listed on the computer monitor at the airport, the conclusion is drawn that there is no flight connecting these two cities. 
The assumption is that all the flights are listed on the monitor, and hence if a flight between two cities is not listed, it may be concluded that there is no such connection. This pattern proceeds from a paradigm of data (a knowledge database) that is not complete and the absence of an entity therefrom Walton (1996, p. 254).

Major Premise: If $A$ were true, $A$ would be known to be true.

Minor Premise: $A$ is not known to be true.

Conclusion: $A$ is false.

The major premise assumes that there has been a search through the knowledge base that would contain $A$ that has supposedly been deep enough so that if $A$ were there, it would be found. The critical questions include considerations of (1) how deep the search has been, and (2) how deep the search needs to be to prove the conclusion that $A$ is false to the required standard of proof in the investigation. In typical instances of the argument from ignorance, the major premise of the argument is not explicitly stated, and has to be inferred from the text by applying the argumentation scheme.

Consider the following example of the argument from lack of evidence. Since there is no evidence that Bob is a spy, even though the National Security Service has carefully searched for evidence that he is a spy, we may conclude that, as far we can tell, Bob is not a spy. This argument from ignorance seems reasonable. However, it is defeasible, because it is possible that Bob has avoided detection as a spy so far. This argument can be put into the following format: if there is evidence of the kind $x$, then $B$ is a spy; there is no evidence of the kind $x$; therefore $B$ is not a spy.

This type of argument is closely related to argument from best explanation. The non-existence of an entity can be regarded as the best possible explanation of the lack of evidence or knowledge thereof. However, in case of a closed-world assumption (the database is known and closed, no further information can flow in) this pattern of reasoning becomes an instance of a deductive pattern of reasoning proceeding from a rule relative to the database.

\section{Revising the current classification system}

The classification system originally proposed in Walton (2005, pp. 234-235) and revised in Walton et al. (2008) consisted in three main categories: reasoning arguments, source-based arguments, and arguments applying rules to cases. Under these three main categories, subcategories and individual schemes were classified. However, this classification system had some problems. The first one is that the category of 'reasoning' was helpful inasmuch as it represented patterns of reasoning that could not fall under the rule-case and source-based arguments. However, this category did not offer any further criteria for a positive (namely not merely exclusive) classification of schemes. It included deductive, abductive, inductive, and causal patterns, without an overarching common characteristic. For this reason, this group was modified and replaced by two further categories, 'discovery arguments' and 'practical reasoning'. Under the first category (discovery arguments) fall arguments that are aimed at establishing rules or entities, namely that do not instantiate a rule, but rather create a new one (arguments establishing rules) or establish the existence of an entity or a property that was not already included in the rule. Arguments from sign and ignorance belong to this latter group, as they a possible and particular (not general) explanation of an event or state of affairs. Practical reasoning is distinguished as a distinct type of arguments, as its conclusion is action-oriented (or an assessment on the desirability of an action) and it is based on considerations bound to values and evaluations of future actions.

On this perspective, rules-based arguments include patterns of reasoning proceeding on various types of rules, namely causal, legal, social, and linguistic in nature. They are basically aimed 
Table 1. Summary of classification of schemes.

\begin{tabular}{|c|c|c|}
\hline \multicolumn{3}{|c|}{$\begin{array}{l}\text { Source-independent arguments } \\
\text { Epistemic reasoning }\end{array}$} \\
\hline Discovery arguments & Applying rules to cases & Source-dependent arguments \\
\hline $\begin{array}{l}\text { 1. Arguments establishing rules } \\
\text { - Argument from a random } \\
\text { sample to a population } \\
\text { - Argument from best } \\
\text { explanation } \\
\text { 2. Arguments finding entities } \\
\text { - Argument from sign } \\
\text { - Argument from ignorance }\end{array}$ & $\begin{array}{l}\text { 1. Arguments based on cases } \\
\text { - Argument from an established } \\
\text { rule } \\
\text { - Argument from verbal } \\
\text { classification } \\
\text { - Argument from cause to effect } \\
\text { 2. Defeasible rule-based arguments } \\
\text { - Argument from example } \\
\text { - Argument from analogy } \\
\text { - Argument from precedent } \\
\text { 3. Chained arguments connecting } \\
\text { rules and cases } \\
\text { - Argument from gradualism } \\
\text { - Precedent slippery slope } \\
\text { argument } \\
\text { - Sorites slippery slope argument }\end{array}$ & $\begin{array}{l}\text { 1. Arguments from position to know } \\
\text { 1.1. Argument from expert opinion } \\
\text { 1.2. Argument from position to know } \\
\text { - Argument from witness testimony } \\
\text { 2. Ad Hominem arguments } \\
\text { 2.1 Direct ad hominem } \\
\text { 2.2 Circumstantial ad hominem } \\
\text { - Argument from inconsistent } \\
\text { commitment } \\
\text { - Arguments attacking personal } \\
\text { 1. Aredibility } \\
\text { 2. Poisoning the well by alleging group } \\
\text { bias } \\
\text { 3. Arguments from popular acceptance } \\
\text { - Argument from popular opinion } \\
\text { - Argument from popular practice }\end{array}$ \\
\hline
\end{tabular}

at classifying entities and drawing defeasible consequences from such defeasible classifications. Such classification can proceed from particular instances (arguments from example or analogy) or from explicit general rules. The defeasible nature of the latter type of patterns lies in the nature of the rules used, and the human limited knowledge that cannot exclude possible exceptions. Verheij (2001, p. 232) proposed that defeasible argumentation schemes fit a form of argument he called modus non excipiens: as a rule, if $P$ then $Q ; P$; it is not the case that there is an exception to the rule that if $P$ then $Q$; therefore $Q$. On his account, modus non excipiens can be used for evaluating defeasible inferences like the Tweety argument: If Tweety is a bird, Tweety flies; Tweety is a bird; therefore, Tweety flies. The arguments can be classified according to Table 1.

The system shown in Figure 4 is a structure that captures many of the most important schemes that have been studied in the argumentation literature so far.

In Figure 4, the schemes are represented as a directed graph structure. It represents a provisional classification system that can be refined as it is integrated with new developments. The classical distinction between source-dependent and source-independent arguments provides the criterion for the first dichotomy (Macagno \& Walton, 2014b). The source dependent arguments are further divided into epistemic and practical arguments, and the former ones are distinguished 


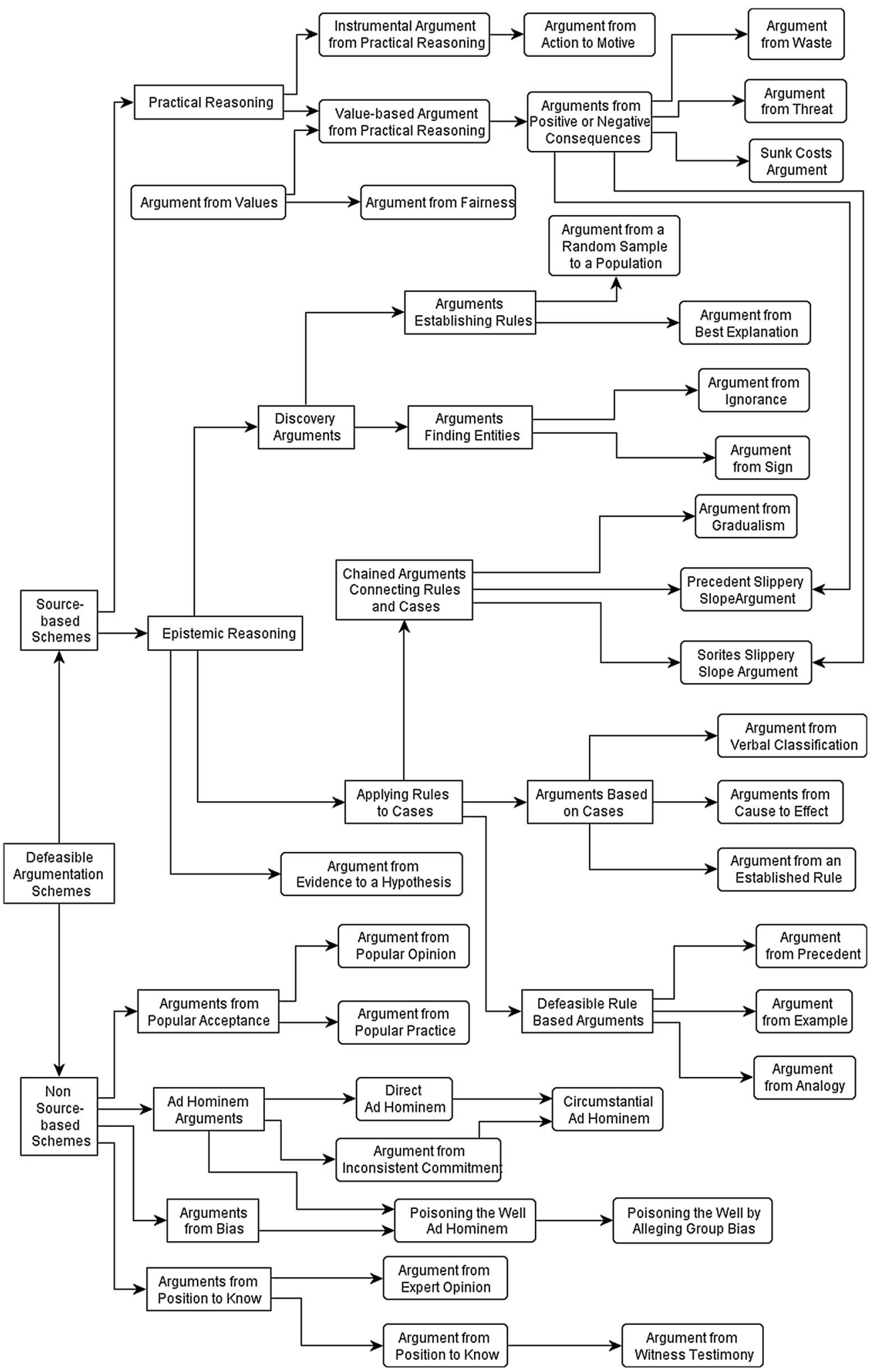

Figure 4. Classification of argumentation schemes. 
between the ones consisting in applying rules to cases and the ones retrieving rules or entities (discovery arguments). These macro-categories can be further specified. In some cases, the various arguments are grouped under more general final classes. In other cases, various types of arguments are subsumed under a more general scheme. Some schemes are more general than others, and for this reason they constitute the genus of some more specific types of argument. Clear examples are provided by external arguments, where sub-schemes are ordered under more encompassing ones.

This classification is not final for two reasons. On the one hand, a potentially high number of types of arguments can be found representing specific applications of more generic patterns. However, this classification system is flexible enough to represent sub-instances of the existing argument schemes. On the other hand, the criterion used for the classification is focused on the structure of the argument and the nature of the generalisation. Other classifications can be introduced and crossed with the present one, based on principles more adequate for specific purposes (such as textual interpretation, for instance).

Finally, it needs to be added that we have not attempted to deal with linguistic arguments, where the argument depends on linguistic considerations such as definitions and classifications (Macagno \& Walton 2014a). The argumentation schemes of this kind recognised by Walton, Reed and Macagno (Walton, Reed \& Macagno 2008) include argument from verbal classification, argument from definition, argument from definition to classification, and the linguistic type of slippery slope argument often identified with the sorites or bald man argument well known in ancient Greek philosophy. Schemes in this category need to be added to Figure 4 to make the classification system more complete. This is left as a project for future work.

\section{Conclusions}

It this paper, it was explained how argumentation schemes are proving to be useful for argument mining, but also how the proliferation of them poses a classification problem. So many schemes have now been recognised, and the relationships among them and the borderlines between them poses problems when attempting to combine the employment of human coders (labellers) along with automated systems to identify types of arguments in natural language discourse. This paper has surveyed recent research offering different systems of classifying schemes, and shown how different ways of classifying schemes depend on the different approaches to formalising schemes, and different desiderata for constructing a classification system.

This paper surveys one particular system in some depth and extends it to provide a new modifiable classification system of the 44 defeasible schemes best known in the literature so far. Among some of the main types of arguments classified in the new system are argument from expert opinion, argument from sign, argument from example, argument from commitment, argument from position to know, argument from lack of knowledge, practical reasoning (argument from goal to action), argument from cause to effect, the SC argument, argument from analogy, ad hominem argument, and the slippery slope argument.

Answers to the question why classifying schemes is useful can be can be derived from the discussion of 'desiderata for building a classification system of schemes' in Section 3. Most important is that a classification system would allow the analyst - an expert, a student, or someone who is hired for coding arguments - to 'situate an argument in relation to other arguments it is related to'. The next step for future research is to build a procedure for achieving such a situating. It is possible, for example, to consider the following procedure: Starting from more general criteria by means of which more general types of schemes can be identified, such as those in Walton (2012), coders could move, step by step, from the most general types through layers of subtypes down to and end point. 
A coder who moves from more general to more specific types needs to know when he or she has reached this end point and can stop. In a 'classical' classification such a stopping rule would usually say: classify as far as it gets. The classification system given in this paper makes it possible to apply this rule. For example, how should a coder know whether the work is already done after identifying an 'argument from analogy', even though there is still an 'argument from precedent' underneath? The answer is to try the next level and see if it works, by examining the text to see whether the given argument fits the special requirement stipulated by the scheme for argument from precedent or not. If so, keep going. If not, stop.

Some work was reported by Hansen and Walton (2013) on problem cases where inter-coder reliability was low, but at the present time we do not have the resources to continue this empirical work, although we are hoping that others will do it. Walton (2012) provided refinements of the rubrics on which the coding was based by providing a set of identity requirements for each scheme. The requirements for each of the schemes treated in this paper have been formulated as a helpful guide for coders in Walton (2012). But we have not yet carried this work of testing our system any further. The intent of the present paper is to build an abstract classification system based on previous work on the schemes. The intent is not to test the system on further empirical work on argument mining, other than to test it by examining some problematic borderline cases and making suggestions on how they might be handled. Empirical investigations are needed to test the proposed classification system and refine it using further examples.

\section{Conflict of interest disclosure statement}

No potential conflict of interest was reported by the authors.

\section{Acknowledgments}

Douglas Walton would like to thank the Social Sciences and Humanities Research Council of Canada for Insight Grant 435-2012-0104. Fabrizio Macagno would like to thank the Fundação para a Ciência ea Tecnologia for the research grant on Argumentation, Communication and Context (PTDC/FIL-FIL/110117/2009).

\section{Notes}

1. Araucaria can be downloaded from http://araucaria.computing.dundee.ac.uk/doku.php.

2. Carneades can be downloaded from http://carneades.github.com/.

\section{References}

Ashley, K. (2006). Case-based reasoning. In A. R. Lodder \& A. Oskamp (Eds.), Information technology and lawyers (pp. 26-60). Amsterdam: Springer.

Atkinson, K., \& Bench-Capon, T. (2007). Practical reasoning as presumptive argumentation using action based alternating transition systems. Artificial Intelligence, 171, 855-874. doi:10.1016/j.artint.2007. 04.009 .

Atkinson, K., Bench-Capon, T., \& McBurney, P. (2005). Arguing about cases as practical reasoning. In G. Sartor (Ed.), Proceedings of the 10th international conference on artificial intelligence and law (pp. 35-44). New York, NY: ACM.

Bench-Capon, T. (2003). Persuasion in practical argument using value-based argumentation frameworks. Journal of Logic and Computation, 13, 429-448. doi:10.1093/logcom/13.3.429.

Bench-Capon, T., \& Prakken, H. (2010). Using argument schemes for hypothetical reasoning in law. Artificial Intelligence and Law, 18, 153-174. doi:10.1007/s10506-010-9094-8.

Bex, F., \& Reed, C. (2011). Schemes of inference, conflict, and preference in a computational model of argument. Studies in Logic, Grammar and Rhetoric, 23, 39-58. 
Clark, K. L. (1978). Negation as failure. In H. Gallaire \& âĂŐJ. Minker (Eds.), Logic and data bases (pp. 293-322). New York, NY: Plenum Press.

Duschl, R. (2008). Science education in three-part harmony: Balancing conceptual, epistemic, and social learning goals. Review of Research in Education, 32, 268-291. doi:10.3102/0091732X07309371.

Feng, V. W., \& Hirst, G. (2011). Classifying arguments by scheme. Proceedings of the 49th annual meeting of the association for computational linguistics: Human language technologies-volume 1 (pp. 987996). Portland (Oregon): Association for Computational Linguistics.

Gordon, T. F., \& Walton D. (2009a). Legal reasoning with argumentation schemes. In C. D. Hafner (Ed.), Proceedings of the 12th international conference on artificial intelligence and law (pp. 137-146). New York, NY: ACM.

Gordon, T. F., \& Walton, D. (2009b). Proof burdens and standards. In I. Rahwan \& G. Simari (Eds.), Argumentation in artificial intelligence (pp. 239-258). Berlin: Springer.

Govier, T. (1992). A practical study of argument. Belmont: Wadsworth.

Greenwood, K., Bench-Capon, T., \& McBurney, P. (2003). Towards a computational account of persuasion in law. In G. Sartor (Ed.), Proceedings of the 9th international conference on artificial intelligence and law (pp. 22-31). New York, NY: ACM.

Grennan, W. (1997). Informal logic. Montreal: McGill-Queen's University Press.

Guarini, M. (2004). A defense of non-deductive reconstructions of analogical arguments. Informal Logic, 24, 153-168.

Hamblin, C. L. (1970). Fallacies. London: Methuen.

Hansen, H., \& Walton, D. (2013). Argument kinds and argument roles in the Ontario provincial election. Journal of Argumentation in Context, 2, 226-258.

Hastings, A. (1963). A reformulation of the modes of reasoning in argumentation (Ph.D. Dissertation, Northwestern University, Evanston, IL).

Juthe, A. (2005). Argument by analogy. Argumentation, 19, 1-27. doi:10.1007/s10503-005-2314-9.

Kienpointner, M. (1992). Alltagslogik: Struktur und Funktion von Argumentationsmustern. Stuttgart: Fromman-Holzboog.

Kim, M., Anthony, R., \& Blades, D. (2012, November 24-27). Argumentation as a tool to understand complexity of knowledge integration. Proceedings of the 2nd international STEM in education conference - Beijing, China (pp. 154-160). Beijing: Beijing Normal University.

Lumer, C., \& Dove, I. J. (2011). Argument schemes-an epistemological approach. In F. Zenker (Ed.), Argumentation: Cognition and community. Proceedings of the ninth international conference of the Ontario society for the study of argumentation (pp. 1-32). Windsor, ON: OSSA.

Macagno, F. (2013). Strategies of character attack. Argumentation, 27, 369-401. doi:10.1007/s10503-0139291-1.

Macagno, F. (2014). Analogy and redefinition. In Systematic approaches to argument by analogy (pp. $73-$ 89). Cham: Springer International.

Macagno, F. (2015). A means-end classification of argumentation schemes. In F. van Eemeren \& B. Garssen (Eds.), Reflections on theoretical issues in argumentation theory (pp. 183-201). Cham: Springer.

Macagno, F., \& Walton, D. (2009). Argument from analogy in law, the classical tradition, and recent theories. Philosophy and Rhetoric, 42, 154-182.

Macagno, F., \& Walton, D. (2011). Reasoning from paradigms and negative evidence. Pragmatics \& Cognition, 19: 92-116.

Macagno, F., \& Walton, D. (2014a). Emotive language in argumentation. New York: Cambridge University Press.

Macagno, F., \& Walton, D. (2014b). Argumentation schemes and topical relations. In G. Gobber \& A. Rocci (Eds.), Language, reason and education (pp. 185-216). Bern: Peter Lang.

Macagno, F., \& Walton, D. (2015). Classifying the patterns of natural arguments. Philosophy \& Rhetoric, $48,26-53$.

Macagno, F., Walton, D., \& Tindale, C. (2014). Analogical reasoning and semantic rules of inference. Revue internationale de philosophie, 270: 419-432.

Mochales, R., \& Moens, M. F. (2011). Argumentation mining. Artificial Intelligence and Law, 19, 1-22. doi:10.1007/s10506-010-9104-x. 
Mochales Palau, R., \& Moens, M. F. (2009). Argumentation mining: The detection, classification and structuring of arguments in text. Proceedings of the 12th international conference on artificial intelligence and law (pp. 98-107). New York, NY: ACM. doi:10.1145/1568234.1568246.

Nussbaum, E. M. (2011). Argumentation, dialogue theory, and probability modeling: Alternative frameworks for argumentation research in education. Educational Psychologist, 46, 84-106. doi:10.1080/ 00461520.2011 .558816$.

Perelman, C., \& Olbrechts-Tyteca, L. (1969). The new rhetoric: A treatise on argumentation. Notre Dame: University of Notre Dame Press.

Prakken, H. (2010). On the nature of argument schemes. In C. Reed \& C. Tindale (Eds.), Dialectics, dialogue and argumentation. An examination of Douglas Walton's theories of reasoning and argument (pp. 167-185). London: College.

Rahwan, I., Banihashemi, B., Reed, C., Walton, D., \& Abdallah, S. (2011). Representing and classifying arguments on the semantic web. The Knowledge Engineering Review, 26: 487-511.

Rapanta, C., Garcia-Mila, M., \& Gilabert, S. (2013). What is meant by argumentative competence? An integrative review of methods of analysis and assessment in education. Review of Educational Research, 83, 483-520. doi:10.3102/0034654313487606.

Reed, C., \& Walton, D. (2003). Applications of argumentation schemes. In H. Hansen, C. Tindale, A. Blair, $\&$ R. Johnson (Eds.), Argumentation and its applications: Proceedings of the 4th OSSA conference (pp. 1-12). Windsor, ON: OSSA.

Reed, C., Walton, D., \& Macagno, F. (2007). Argument diagramming in logic, law and artificial intelligence. The Knowledge Engineering Review, 22, 87-109. doi:10.1017/S0269888907001051.

Reiter, R. (1980). A logic for default reasoning. Artificial Intelligence, 13, 81-132. doi:10.1016/0004-3702 (80)90014-4.

Rowe, G., Macagno, F., Reed, C., \& Walton, D. (2006). Araucaria as a tool for diagramming arguments in teaching and studying philosophy. Teaching Philosophy, 29, 111-124.

Sartor, G., Walton, D., Macagno, F., \& Rotolo, A. (2014). Argumentation schemes for statutory interpretation: A logical analysis. In R. Hoekstra (Ed.), Legal knowledge and information systems: JURIX 2014: The twenty-seventh annual conference (pp. 11-20). Amsterdam: IOS Press.

Verheij, B. (2001). Legal decision making as dialectical theory construction with argumentation schemes. Proceedings of the 8th international conference on artificial intelligence and law (pp. 225-226). New York, NY: ACM.

Verheij, B. (2008). About the logical relations between cases and rules. In E. Francesconi, G. Sartor, \& D. Tiscornia (Eds.), Legal knowledge and information systems. JURIX 2008: The twenty-first annual conference (pp. 21-32). Amsterdam: IOS Press.

Walton, D. (1990). What is reasoning? What is an argument? The Journal of Philosophy, 87, 399-419.

Walton, D. (1996). Argumentation schemes for presumptive reasoning. Mahwah: Lawrence Erlbaum.

Walton, D. (1998). Ad hominem arguments. Tuscaloosa: University of Alabama Press.

Walton, D. (2002). Legal argumentation and evidence. University Park: The Pennsylvania State University Press.

Walton, D. (2005). Argumentation methods for artificial intelligence and law. Berlin: Springer.

Walton, D. (2006). Fundamentals of critical argumentation. New York, NY: Cambridge University Press.

Walton, D. (2011). Argument mining by applying argumentation schemes. Studies in Logic, 4, 38-64.

Walton, D. (2012). Using argumentation schemes for argument extraction: A bottom-up method. International Journal of Cognitive Informatics and Natural Intelligence, 6, 33-61. doi:10.4018/jcini.20120 70103.

Walton, D., \& Krabbe, E. (1995). Commitment in dialogue. Albany: State University of New York Press.

Walton, D., Reed, C., \& Macagno, F. (2008). Argumentation schemes. Fundamentals of critical argumentation. New York: Cambridge University Press.

Warnick, B., \& Kline, S. L. (1992). The new rhetoric's argument schemes: A rhetorical view of practical reasoning. Argumentation \& Advocacy, 29, 1-15.

Westberg, D. (2002). Right practical reason: Aristotle, action, and prudence in Aquinas. Oxford: Clarendon Press. 